thuốc lá ở sinh viên đặc biệt các khối sinh viên năm giữa khóa học

\section{TÀI LIỆU THAM KHẢO}

1. SAMHSA, Center for Behavioral Statistics and Quality. National Survey on Drug Use and Health, 2018 and 2019. Table 6.21B-Types of Illicit Drug, Tobacco Product, and Alcohol Use in Past Month among Persons Aged 18 to 22 .

2. Salas-Gomez $D$, Fernandez-Gorgojo $M$, Pozueta A, et al. Binge Drinking in Young University Students Is Associated with Alterations in Executive Functions Related to Their Starting Age. PLoS One. 2016; 11(11): e0166834.

3. Heather $N$, Partington $S$, Partington $E$, et al. Alcohol use disorders and hazardous drinking among undergraduates at English universities. Alcohol Alcohol. 2011; 46(3): 270.

4. UNFPA. Báo cáo quốc gia về thanh niên Viêt Nam. 2015; tr 52.

5. Phạm Bích Diệp. Bối cảnh uông rượu, bia của sinhi viên Việt Nam. Tạp chí Y học dự phòng. 2015; 6 (166): 470 .
6. Lê Trận Tuấn Anh, Nguyễn Thị Minh Ngọc, Nguyễn Thị Thanh Ngân. Kiến thức, thái độ hành vi uống rươu bia của sinh viên đa khoa hế dài hạn trường Đ̇ại học $Y$ Dược Hải Phòng năm 2015. Tap chí Y họ dư phòng. 2015; 11(171):29.

7. WHO. International Classification of Diseases and Related Health Problems, 10th Revision (version for 2007) Geneva, Switzerland. 2007.

8. WHO. Alcohol - September 2018. Truy câp ngày 01/3/2021. https://www.who.int/news-room/factsheets/detail/alcohol

9. Dương Hải. Uống 1 lon bia/ngày cũng tăng nguy cơ mắc ung thư, vậy mà người Việt "không say, không về". Báo Sức khỏe và đời sống. 2019. Truy cập 01/03/2021. https://suckhoedoisong.vn/uong1-lon-bia-ngay-cung-tang-nguy-co-mac-ung-thuvay-ma-nguoi-viet-khong-say-khong-ve169158054.htm

10. Phan Văn Sang, Hồ Thị Thùy, Trân Xuân An. Thực trạng lạm dụng rượu bia và các yếu tố liên quản của sinhi viên tại một số trường Đại học và Cao đẳng ở thành phố Huễ năm 2016. Tạp chí Y học dự phòng. 2017; 27(8):366-373.

\title{
MộT SỐ YẾU TỐ LIÊN QUAN ĐẾN KẾT QUẢ ĐIỀU TRI NHIỄM KHUẨN HÔ HẤP CẤP TÍNH TAI KHOA KHÁM VÀ ĐIỀU TRI 24 GIỜ, BÊ̂NH VIỆN NHI TRUNG ƯO'NG.
}

\section{TÓM TẮT}

Mục tiêu: Tìm hiểu môt số yếu tố liên quan đến kết quả điều trị nhiễm khuẩn hô hấp cấp tính tại Khoa khám và điêu trị 24 giờ, Bệnh viện Nhi Trung ương. Đô̂́i tượng: Trẻ từ 2 tháng đến dưới 60 tháng tuổi, diễn biển cấp tính dưới 7 ngày từ khi khởi phát bệnh được khám và điều trị nội trú tại khoa. Phương pháp nghiên cứu: Nghiên cứu mô tả tiến cứu. Kết quả: Nghiên cứu trên 203 bệnh nhân: tỷ lệ BN nam/ nữ là $1,9 / 1$, tuổi trung bình là $17,1 \pm 12,1$ (tháng), chủ yếu trên 12 tháng tuổi. BN nhập viện do NKHHDCT (76,9\%), gấp 3,3 lần số BN nhập viện do NKHHTCT, viêm phế quản phổi $(38,9 \%)$ chiểm tỷ lê cao nhất. BN ra viện tại khoa $24 \mathrm{~h}$ chiếm $84,7 \%$, tỷ lệ BN nặng lên cần chuyển khoa chiếm $15,3 \%$, không có bệnh nhân tử vong hoặc xin về. Không có sự khác biệt về kết quả điều tri NKHHCT ở hai giới nam và nữ, giữa nhóm trên và dưới 12 tháng, giá trị bạch câu, $C R P$, kết quả nuôi cấy dịch ty hâu, nhiếm RSVi. Thời gian nằm viện trung vị của nhóm NKHHTCT ngắn hơn NKHHDĆT. Kết luân: Trẻ nam găp nhiều hơn nữ, chủ yếu là nhóm trền 12 tháng tuổi, viêm đường hô hấp dưới và VPQP

*Bệnh viện Nhi trung ương

Chịu trách nhiệm chính: Pham Ngọc Toàn

Email: ngoctoancard@yahoo.com

Ngày nhận bài: 21.6.2021

Ngày phản biên khoa họ: 16.8.2021

Ngày duyệt bài: 24.8.2021
Phạm Ngọc Toàn*, Lã Thị Bích Hồng*

chiếm phần lớn. Không có sự khác biệt về kết quả điều trị liên quan tới độ tuổi, giới tính, số lượng bach cầu, CRP, kết quả nuôi cấy DTH, nhiễm RSV. Thời gian nằm viên của NKHHTCT ngắn hơn so với NKHHDCT

Tư khóa: Nhiễm khuẩn hô hấp trên và dưới, điều trị

\section{SUMMARY}

SOME FACTORS RELATED TO THE RESULTS OF TREATMENT OF ACUTE RESPIRATORY

TRACT INFECTIONS AT THE 24-HOUR EXAMINATION AND TREATMENT DEPARTMENT, NATIONAL CHILDREN'S HOSPITAL

Objective: To find out some factors related to the results of treatment of acute respiratory infections at the 24-hour examination and treatment department, National Children's Hospital. Subjects: Children from 2 months to less than 60 months old, with acute period less than 7 days, were examined and treated inpatient at the department. Research Methods: A prospective descriptive study. Results: A study on 203 patients the boy/girl ratio was $1.9 / 1$, the mean age was $17.1 \pm 12.1$ (months), mainly over 12 : months old. Patients hospitalized due to acute lower respiratory tract infections $(76.9 \%), 3.3$ times higher than the number of patients hospitalized due to acute upper respiratory tract infections, bronchopneumonia $(38.9 \%)$ accounted for the highest rate. Patients were discharged from the $24 \mathrm{~h}$ ward, accounting for $84.7 \%$, the rate of patients getting worse and needing to be transferred to high level accounted for $15.3 \%$, no 
patient died. There was no differences in treatment outcomes for acute respiratory infections related to sex, between groups above and below 12 months, white blood cell values, CRP, nasopharyngeal fluid culture, RSV infection. The median hospital stay of the acute upper respiratory tract infection group was shorter than that of the acute lower respiratory tract infection. Conclusion: Boys are more common than girls, mainly over 12 months old; lower respiratory tract infections, especially bronchopneumonia, accounted for the majority. There were no differences in treatment outcomes related to age, sex, white blood cell count, CRP, nasopharyngeal culture results, RSV infection. Hospital stay for acute upper respiratory tract infections is shorter than for acute lower respiratory tract infections

Keywords: Upper and lower respiratory tract infections, treatment

\section{I. ĐẠT VẤN ĐỀ}

Nhiễm khuẩn hô hấp cấp tính (NKHHCT) là bệnh lý phổ biến nhất đồng thời cũng là bệnh lý có tỷ lệ tử vong cao nhất ở trẻ em. Trung bình mỗi năm, môt trẻ em có thể bi từ 3-6 đợt nhiễm khuẩn hô hấp cấp tính (NKHHCT)[1]. Theo nghiên cứu của Yorita và cs (2003), tî lệ nhập viện do các bệnh lý nhiễm khuẩn chiếm khoảng $42,8 \%$ số trẻ em phải nhập viện, trong đó nhiễm khuẩn hô hấp dưới cấp (NKHHDCT) chiếm khoảng 59\% [2].

Tại Việt Nam, NKHHCT ở trẻ em là bệnh đứng hàng đầu về tỷ lệ mắc bệnh và tỷ lệ tử vong, viêm phế quản phổi có tỷ lệ tử vong đứng đầu trong các bệnh lý đường hổ hấp (75\%), chiếm $21 \%$ so với tổng số tử vong chung ở trẻ [3]. Điều quan trọng nhất trong thực hành lâm sàng là cần chẩn đoán đúng và xử lý kịp thời NKHHCT để tránh suy hô hấp- nguyên nhân hàng đầu gây tử vong.

Khoa khám và điều trị 24 giờ với đặc thù là một khoa khám chữa bệnh ban đâu, tiếp nhận những $B N$ điều trị với thời gian ngắn và mức độ bênh không nặng, trong đó đa phần là bênh lý hồ hấp. Tuy nhiên, nếu BN có diễn biến năng lên, cần thở oxy hoặc các biến chứng có thể đe dọa tính mạng thì Bì sẽ được chuyển sang khoa cấp cứu hoăc các đơn vị chuyên khoa sâu như khoa hô hấp, điều trị tích cực. Do vậy, chúng tôi tiến hành nghiên cứu nhằm: Tìm hiểu "một số yếu tố liên quan đến kết quả điều trị nhiếm khuẩn hô hấp cấp tính tại Khoa khám và điều trị 24 giờ, Bệnh viện Nhi Trung ương"

II. ĐỐI TƯợNG VÀ PHƯƠNG PHÁP NGHIÊN CỨU

2.1. Địa điểm và thời gian nghiên cứu. Nghiên cứu được tiến hành tại Khoa khám và điều trị 24 giờ- Bệnh viện Nhi Trung ương trong thời gian từ ngày 01/07/2018 đến ngày 31/06/ 2019.
2.2. Đối tượng nghiên cứu. Bệnh nhân có độ tuổi từ 2 tháng đến dưới 60 tháng tuổi được chẩn đoán NKHHCT đến khám và có chỉ định nhập viên tai Khoa khám và điều trị 24 giờ.

\subsubsection{Tiêu chuẩn chơn bệnh nhân}

- Bệnh nhân có độ tuổi từ 2 tháng đến dưới 60 tháng tuổi.

- Bệnh diễn biến cấp tính dưới 7 ngày từ khi khởi phát bệnh.

- Bênh nhân được chẩn đoán NKHHCT thuộc các nhóm bệnh có tiêu chuẩn chẩn đoán theo phác đồ của bộ y tế.

- Bố mẹ bệnh nhân đồng ý tham gia vào nghiên cứu.

\subsubsection{Tiêu chuẩn loại trừ}

- Bệnh nhân đã điều trị ở bệnh viện tuyến dưới.

- Bệnh nhân mắc nhiễm trùng hô hấp thứ phát sau: Dị vật đường thở, hen phế quản, đuối nước, sặc dầu ...

- Bệnh nhân ho, khò khè do các nguyên nhân mạn tính: Hen phế quản, mềm sụn thanh quản, chèn ép từ ngoài vào như hạch bạch huyết...

2.3.3. Tiêu chuẩn đánh giá kết quả điêuu trị:

- Kết quả điều trị tốt: BN điều trị ổn định, được ra viện tại khoa 24 giờ, không có biến chứng.

- Kết quả điều trị không tốt: $B N$ có biến chứng suy hô hấp, nặng lên cần chuyển sang các khoa như khoa hô hấp, khoa cấp cứu, khoa điêu trị tích cực.

- Điều trị NKHHCT được tuân thủ theo phác đồ của bộ y tế

\subsection{Phương pháp nghiên cứu}

* Thiết kế nghiên cứu: Nghiên cứu mô tả tiến cứu.

* Cỡ mẫu nghiên cứu: chọn mẫu thuận tiện

* Các bước tiến hành nghiên cứu.

- Lựa chọn những bệnh nhân đến khám được chẩn đoán bệnh NKHHCT và có chỉ định nhập viện điều trị tại khoa khám và điều trị 24 giờ.

- Khai thác các chỉ số nghiên cứu theo mẫu bệnh án nghiên cứu.

- Theo dõi kết quả điều trị bệnh nhân.

\section{KẾT QUẢ NGHIÊN CỨU}

1. Đặc điểm chung của đối tượng nghiên cứu. Trong thời gian nghiên cứu, chúng tôi đã lựa chọn được 203 bệnh nhân. Kết quả nghiên cứu như sau

Chẩn đoán bênh tai thời điểm nhâp viện

Bảng 1: Phẩn bồ chẩn đoán bệnh lúc nhập viện

\begin{tabular}{|c|c|c|c|c|}
\hline \multicolumn{2}{|c|}{$\begin{array}{c}\text { Chấn đoán lúc } \\
\text { nhập viện }\end{array}$} & $\begin{array}{c}\text { Số } \\
\text { BN }\end{array}$ & $\begin{array}{c}\text { Tỷ lệ } \\
(\%)\end{array}$ & $\begin{array}{c}\text { Tống } \\
\text { (\%) }\end{array}$ \\
\hline \multirow{2}{*}{ NKHHTCT Tiêm mũi họng } & 34 & 16,7 & \multirow{2}{*}{23,1} \\
\cline { 2 - 4 } & Viêm tai giữa & 13 & 6,4 & \\
\hline
\end{tabular}




\begin{tabular}{|c|c|c|c|c|}
\hline \multirow{4}{*}{ NKHHDCT } & Viêm thanh quả & 7 & 3,5 & \multirow{5}{*}{76,9} \\
\hline & \multirow{2}{*}{\begin{tabular}{|c} 
Viêm phế quản \\
$\begin{array}{c}\text { Viêm tiểu phế } \\
\text { quản }\end{array}$
\end{tabular}} & 26 & 12,8 & \\
\hline & & 44 & 21,7 & \\
\hline & $\begin{array}{c}\text { Viêm phế quản } \\
\text { phổi }\end{array}$ & 79 & 38,9 & \\
\hline & Tốn & 203 & 100 & \\
\hline
\end{tabular}

Nhận xét: Đa số BN nhập viện do NKHHDCT $(76,9 \%)$, gấp 3,3 lần số $\mathrm{BN}$ nhập viện do NKHHTCT, viêm phế quản phổi $(38,9 \%)$ chiếm tỷ lệ cao nhất

Phân bố BN theo tuổi, giới tính

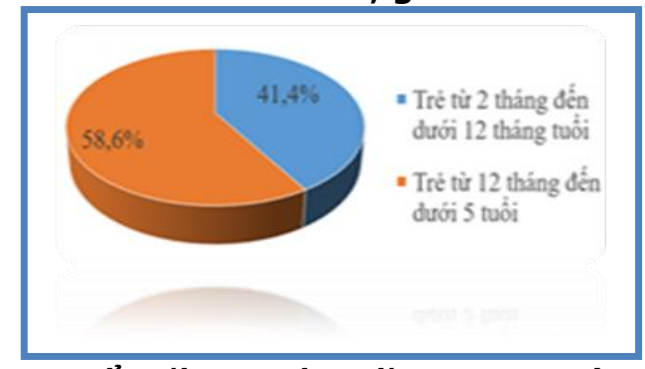

Biểu đồ 1: Phân bố BN theo giới

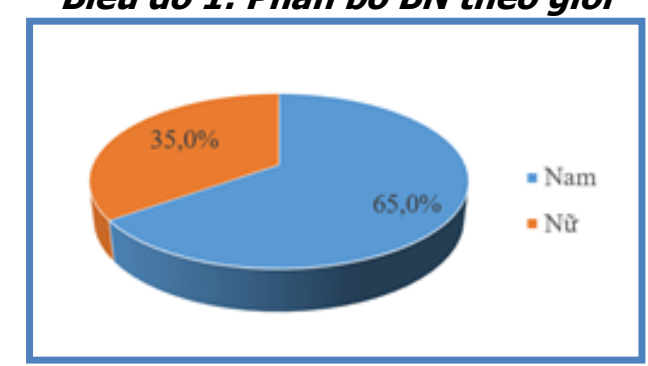

Biểu đồ 2: Phân bố BN theo nhóm tuổi

Nhận xét: Tỷ lệ BN nam/ nữ là 1,9/1. Tuổi trung bình của BN trong nhóm nghiên cứu là 17,1 $\pm 12,1$ tháng. Trẻ nhỏ nhất 2 tháng tuổi, trẻ lớn nhất 58 tháng tuổi, chủ yếu trẻ trên 12 tháng tuổi.

Kết quả điều trị

Bảng 2: Kêt quả điều trị chung của nhóm nghiên cứu

\begin{tabular}{|c|c|c|c|}
\hline \multicolumn{2}{|c|}{ Kết quả điêu trị } & $\begin{array}{c}\text { Số BN } \\
(\mathbf{n = ~ 2 0 3 )}\end{array}$ & $\begin{array}{c}\text { Tỷ lệ } \\
\text { (\%) }\end{array}$ \\
\hline $\begin{array}{c}\text { Kết quả } \\
\text { điêuu trị }\end{array}$ & Tốt & 172 & 84,7 \\
\cline { 2 - 4 } & Không tốt & 31 & 15,3 \\
\hline $\begin{array}{c}\text { Thời gian } \\
\text { điêu trị }\end{array}$ & $<24 \mathrm{~h}$ & 21 & 10,3 \\
\cline { 2 - 4 } & $\geq 24 \mathrm{~h}$ & 182 & 89,7 \\
\hline \multirow{2}{*}{$\begin{array}{c}\text { Thời gian điều trị trung } \\
\text { vị (IQR) }\end{array}$} & 4 \\
\hline
\end{tabular}

Nhận xét: Tỷ lệ BN ổn định được ra viện tại khoa $24 \mathrm{~h}$ chiếm $84,7 \%$. Tỷ lệ BN nặng lên cần chuyển khoa (không tốt) chiếm 15,3\%. Không có bệnh nhân nào tử vong hoặc xin về. Tỷ lệ $B N$ ra viện trước 24 giờ là $10,3 \%$. Thời gian điều trị trung vị là 4 ngày. IQR: 3 và 6 ngày

2. Một số yếu tố liên quan đến kết quả điêuu trị NKHHCT ở trẻ em.

Liên quan giữa nhóm tuổi và kêt quả điêu trị

Bảng 3: Kêt quả điều trị NKHHCT theo nhóm tuối

\begin{tabular}{|c|c|c|c|c|}
\hline \multirow{2}{*}{$\begin{array}{c}\text { Kết quả } \\
\text { điêuu trị } \\
n=203\end{array}$} & $\begin{array}{c}|c| \\
\text { Từ 2 }-\leq \\
12 \text { tháng } \\
\mathrm{n}(\%)\end{array}$ & $\begin{array}{c}<12 \text { đến } \leq \\
60 \text { tháng } \\
\mathrm{n}(\%)\end{array}$ & \multirow{2}{*}{ Tổng } & $\mathbf{p}$ \\
\hline Tốt & $68(81)$ & $104(87,4)$ & $172(84,7)$ & 0 \\
\hline $\begin{array}{c}\text { Không } \\
\text { tốt }\end{array}$ & $16(19)$ & $15(12,6)$ & $31(15,3)$ & $\begin{array}{c}20 \\
9\end{array}$ \\
\hline Tổng & $84(41,4)$ & $119(8,6)$ & $203(100)$ & \\
\hline
\end{tabular}

Nhận xét: Không có sự khác biệt về kết quả điều trị giữa nhóm trên và dưới 12 tháng

Liên quan giữa giới tính và kết quả điêu trị

Bảng 4: Kết quả điều trị NKHHCT theo giới tính

\begin{tabular}{|c|c|c|c|c|}
\hline \multirow{2}{*}{$\begin{array}{l}\text { Kết quả } \\
\text { điêuu trị } \\
n=203\end{array}$} & \multicolumn{2}{|c|}{ Giới } & \multirow[b]{2}{*}{ Tổng } & \multirow[b]{2}{*}{$\mathbf{p}$} \\
\hline & $\begin{array}{c}\text { Nam n } \\
(\%)\end{array}$ & $\begin{array}{l}\text { Nữ n } \\
(\%)\end{array}$ & & \\
\hline Tốt & $\begin{array}{c}111 \\
(84,1)\end{array}$ & $\begin{array}{c}61 \\
(85,9)\end{array}$ & $\begin{array}{c}172 \\
(84,7)\end{array}$ & \multirow{3}{*}{0,730} \\
\hline $\begin{array}{l}\text { Không } \\
\text { tốt }\end{array}$ & $\begin{array}{c}21 \\
(15,9)\end{array}$ & $\begin{array}{c}10 \\
(14,1)\end{array}$ & $\begin{array}{c}31 \\
(15,3)\end{array}$ & \\
\hline Tống & $132(65)$ & $71(35)$ & 203 & \\
\hline
\end{tabular}

Nhận xét. Không có sự khác biêt về kết quả điều trị NKHHCT ở hai giới nam và nữ.

Liên quan giữa vị trí NKHHCT và thời gian nằm viện

Bảng 5: Liên quan giữa vị trí NKHHCT và thời gian nằm viện

\begin{tabular}{|c|c|c|}
\hline \multirow{2}{*}{$\begin{array}{l}\text { Thời gian nằm } \\
\text { viện } n=203\end{array}$} & \multicolumn{2}{|c|}{ Vị trí NKHHCT } \\
\hline & NKHH'TCT & NKHHDCT \\
\hline Trung vị (ngày) & 3 & 5 \\
\hline IQR (ngày) & $2-4$ & $3-7$ \\
\hline $\mathrm{p}$ & $<0$ & \\
\hline
\end{tabular}

Nhận xét: Thời gian nằm viện trung vị của nhóm NKHHTCT ngắn hơn NKHHDCT, sự khác biệt có ý nghĩa thống kê với $p<0,001$.

Liên quan giữa số lượng bạch câu với kết quả điêu trị.

Bảng 6: Liền quan giữa số lượng bạch cầu với kêt quả điều trị

\begin{tabular}{|c|c|c|}
\hline \multirow{2}{*}{$\begin{array}{c}\text { Số lượng bạch } \\
\text { câu } \mathbf{n = 2 0 3}\end{array}$} & \multicolumn{2}{|c|}{ Kết quả điêu trị } \\
\cline { 2 - 3 } & Tốt & Không tốt \\
\hline Trung vị (G/I) & 13,8 & 13,4 \\
\hline $\mathrm{IQR}(\mathrm{G} / \mathrm{I})$ & $9,8-17,7$ & $9,9-17,3$ \\
\hline $\mathrm{P}$ & \multicolumn{2}{|c|}{0,923} \\
\hline
\end{tabular}

Nhận xét: Số lượng bạch câu trung vị ở hai nhóm có kết quả điều trị tốt và không tốt không có sự khác biệt có ý nghĩa thống kê với $p>0,05$.

Liên quan giữa nồng độ CRP với kết quả 
điêuu trị

Bảng 7: Liên quan giữa nồng độ CRP với kêt quả điều trị

\begin{tabular}{|c|c|c|}
\hline Nồng độ CRP & \multicolumn{2}{|c|}{ Kết quả điều trị } \\
\cline { 2 - 3 } $\mathbf{n = 2 0 3}$ & Tốt & Không tốt \\
\hline Trung vị (mg/l) & 10,9 & 15,0 \\
\hline IQR $(\mathrm{mg} / \mathrm{l})$ & $3,5-31,9$ & $5,2-26,9$ \\
\hline P & \multicolumn{2}{|c|}{0,541} \\
\hline
\end{tabular}

Nhận xét: Nồng độ CRP trung vị ở hai nhóm có kết quả điều trị tốt và không tốt không có sự khác biệt có ý nghĩa thống kê với $p>0,05$.

Liên quan giữa một số đặc điểm vi sinh và kết quả điều trị

Bảng 8: Liên quan giữa nhiễm vi khuân và kêt quả điều trị

\begin{tabular}{|c|c|c|c|c|}
\hline \multirow{2}{*}{$\begin{array}{c}\text { Kết quả } \\
\text { điêu trị }\end{array}$} & $\begin{array}{c}\text { Cấy dịch ty. hâu } \\
\text { Dương } \\
\text { tính(n,\%) }\end{array}$ & $\begin{array}{c}\text { Am tính } \\
(\mathrm{n}, \%)\end{array}$ & \multirow{2}{*}{ Tổng } & p \\
\hline Tốt & $2(68,6)$ & $62(82,7)$ & $86(78,2$ & \\
\hline Không tốt & $11(31,4)$ & $13(17,3)$ & $24(21,8$ & \multirow{2}{*}{0,095} \\
\hline Tổng & $\begin{array}{c}\mathbf{3 5} \\
\mathbf{( 3 1 , 8 )}\end{array}$ & $\begin{array}{c}\mathbf{7 5} \\
\mathbf{( 6 8 , 2 )}\end{array}$ & $\begin{array}{c}\mathbf{1 1 0} \\
\mathbf{( 1 0 0 )}\end{array}$ & \\
\hline
\end{tabular}

Tỷ lệ dương tính với vi khuấn là $35 / 110$ $(31,8 \%)$. Trong đó, phế cầu là nguyên nhân hay gặp nhất với 13 BN $(37,1 \%)$, tiếp đến là Haemophilus Influenza với 11 BN (31,4\%), Moraxella carrtahalis $(25,7 \%)$, các căn nguyên khác ít gặp (5,7\%). Không có sự khác biệt có ý nghĩa thống kê về kết quả điều trị giữa 2 nhóm có kết quả cấy vi khuẩn dương tính và âm tính.

Bảng 9: Liên quan giữa nhiếm RSV và kêt quả điều trị

\begin{tabular}{|c|c|c|c|c|}
\hline \multirow[b]{2}{*}{$\begin{array}{l}\text { Kết quả } \\
\text { điều trị }\end{array}$} & \multicolumn{2}{|c|}{ RSV } & \multirow[b]{2}{*}{ Tổng } & \multirow[b]{2}{*}{$\mathbf{p}$} \\
\hline & $\begin{array}{c}\text { Dương tính } \\
(\mathrm{n}, \%)\end{array}$ & $\begin{array}{c}\text { Ám tính } \\
(n, \%)\end{array}$ & & \\
\hline Tốt & $15(83,3)$ & $51(82,3)$ & $66(82,5)$ & \multirow{3}{*}{1,00} \\
\hline $\begin{array}{c}\text { Không } \\
\text { tốt }\end{array}$ & $3(16,7)$ & $11(17,7)$ & ,5) & \\
\hline Tống & $18(22,5)$ & $62(77,5)$ & $80(100)$ & \\
\hline
\end{tabular}

Nhận xét: Không có sự khác biệt có ý nghĩa thống kê về kết quả điều trị giữa nhóm có nhiễm RSV và không nhiễm RSV.

\section{BÀN LUÂN}

4.1 Một số đặc điểm chung của đối tượng nghiên cứu

* Đặc điểm về giới tính: Tỷ lệ trẻ trai nhập viện vî̀ NKHHCT ở nam nhiều hởn nữ. Nghiển cứu này có kết quả tương tự như một số nghiên cứu trong và ngoài nước khác. Nghiên cứu của Thanh Minh Hùng (2016) trên 102 BN NKHHCT thì tỷ lệ nam/nữ là 2,2. Theo Taksande A.M (2015) nghiên cứu trên 300 BN NKHHCT tỷ lệ nam/nữ là $2 / 1$ [4].
* Tuối: Theo biểu đồ 1, nhóm trẻ từ 2 tháng đến dưới 12 tháng chiếm tỷ lệ $41,4 \%$. Theo Thanh Minh Hùng (2016), nhóm trẻ từ 2 tháng đến dưới 12 tháng chiếm tỷ lệ 30,4\%, độ tuổi trung bình của nhóm nghiên cứu là $17,1 \pm 1,4$ tháng [5]. Theo Quách Ngọc Ngân, nghiên cứu trẻ từ 2 tháng đến 5 tuổi tại Bệnh viện Nhi Đồng Cần Thơ trong 196 trẻ có $48 \%$ trẻ dưới 12 tháng [6]. Theo Taksande A.M (2015) nghiên cứu trên 300 BN NKHHCT nhóm trẻ từ 2 tháng đến dưới 12 tháng chiếm tỷ lệ $33,3 \%$, nhóm 12 tháng đến dưới 5 tuổi chiếm tỷ lệ $50 \%$ [4].

* Chẩn đoán bệnh tại thời điểm nhập viện: Theo bảng 1 , tỷ lệ nhập viện chủ yếu là NKHHDCT $(76,9 \%)$, tỷ lệ NKHHTCT thấp hơn $(23,1 \%)$, trong đó, viêm phế quản phổi chiếm tỷ lệ cao nhất $(38,9 \%)$. Kết quả này phù hợp với nghiên cứu của một số tác giả khác. Theo Thanh Minh Hùng (2016), tỷ lệ trẻ nhập viện do NKHHDCT chiếm tỳ lệ $(69,6 \%)$, NKHHTCT chiếm tỷ lệ thấp $(30,4 \%)$, trong đó viêm phổi chiếm tỷ lệ cao nhất $(58,8 \%)$ [5]. Nghiên cứu của Felman A.S trên 630 BN NKHHCT, tỷ lệ NKHHDCT (72\%), NKHHTCT (28\%) [7].

* Kêt quả điều trị chung của nhóm BN nghiên cứu: Kết quả điều trị được chỉ ra trong bảng 2. Nghiên cứu được tiến hành trên $203 \mathrm{BN}$ NKHHCT; điều trị ổn định, ra viện tại khoa 24h $(84,7 \%)$ và $B N$ nặng cần chuyển sang khoa cấp cứu, hô hấp hoặc điều trị tích cực $(15,3 \%)$. Không $\mathrm{BN}$ nào tử vong hoặc nặng xin về. Trong 31 BN có diễn biến nặng lên cần chuyển khoa, có $20 \mathrm{BN}(64,5 \%)$ chuyển khoa hô hấp, $5 \mathrm{BN}$ $(16,1 \%)$ chuyển khoa cấp cứu, 2 BN $(6,5 \%)$ chuyển khoa điều trị tích cực và $4 \mathrm{BN}$ chuyển đên các khoa khác trong bênhi viên vì các bênh lý kèm theo. Đây cũng là hợp lý vì khoa 24 giờ chủ yếu tiếp nhận bệnh nhân ban đầu và khi bệnh nhân có diễn biển bất thường thì sẽ chuyển đi các chuyên khoa phù hợp.

4.2 Một số yếu tố liên quan đến kết quả điêu trị NKHHCT ở trẻ em.

* Liên quan giữa nhóm tuổi và kêt quả điều trị: Tỷ lẹ trẻ được điều trị ổn định, ra viên tại khoa 24h (tốt) ở nhóm trẻ từ 2 tháng đến dưới 12 tháng là $81 \%$ và ở nhóm trẻ từ 12 tháng đến dưới 5 tuổi là $87,4 \%$. Tỷ lệ trẻ có biểu hiện nặng lên, cần chuyển khoa (không tốt) ở nhóm trẻ từ 2 tháng đến dưới 12 tháng là $19 \%$ và ở nhóm trẻ từ 12 tháng đến dưới 60 tháng tuổi là 12,6\%. Tuy nhiên, kết quả điều trị (tốt, không tốt) ở hai nhóm tuổi không có sự khác biêt có ý nghĩa thống kê $(p>0,05)$. Điều này có thể được lý giải do $\mathrm{BN}$ nhập khoa khám và điều trị $24 \mathrm{~h}$ 
chủ yếu là đối tượng $B N$ có mức đô bênh nhe hoặc vừa, số lượng bệnh nhi nặng lên cần chuyển sang các khoa khác không nhiều, sự khác biệt về kết quả điều trị ở các nhóm tuổi không có sự khác biêt.

* Liên quan giữa giới tính và kêt quả điều trị: Tỷ lệ trẻ có kết quả điều trị tốt ở nhóm trẻ nam là $84,1 \%$ và ở nhóm nữ là $85,9 \%$. Tỷ lê trẻ có kết quả điều trị không tốt ở nhóm nam là $15,9 \%$ và nhóm nữ là $14,1 \%$. Tuy nhiên, kết quả điều trị (tốt, không tốt) ở hai nhóm nam và nữ không có sự khác biệt có ý nghĩa thống kê $(p>0,05)$. Mặc dù, trẻ nam nhâp viện do NKHHCT chiếm tỷ lệ cao hơn trẻ nữ. Tuy nhiên, không có sự khác biệt về kết quả điều trị của hai nhóm bênh lý này.

* Liền quan giứa vi trí NKHHCT và thời gian nằm viện: Thời gian nằm viện trung vị của nhóm NKHHTCT là 3 (ngày) với IQR: 2 và 4 ngày. BN nằm ít nhất là 1 ngày và dài nhất là 23 ngày. Thời gian nằm viện trung vị của nhóm NKHHTCT là 5 ngày, IQR: 3 và 7 ngày, trong đó $\mathrm{BN}$ nằm ít nhất 1 ngày và nhiều nhất là 25 ngày. So sánh thời gian nằm viện trung vị của hai nhóm NKHHTCT và NKHHDCT, sự khác biêt về thời gian điều trị giữa 2 nhóm có nghĩa thống kê với $p<0,01$. Như vậy, nhóm $B N$ được chẩn đoán NKHHDCT có thời gian nằm viện lâuu hơn nhóm NKHHTCT.

Nghiên cứu của Jorge HJ (2019) được thực hiện trên 638 BN chẩn đoán NKHHCT tại $\mathrm{EI}$ Salvador và Panama cho thây: Với nhóm không nằm khoa điều trị tích cực thời gian nằm viện trung bình là 4 ngày, trong số đó $\mathrm{BN}$ nằm viện ngắn nhất là 3 ngày, dài nhất là 6 ngày. Với nhóm $\mathrm{BN}$ có nằm điều trị tại khoa điêu trị tích cực thì thời gian nằm viện trung bình 16 ngày, ngắn nhất là 13 ngày và dài nhất là 22 ngày. Thời gian nằm tại khoa điều trị tích cực trung bình là 5 ngày [8].

* Liên quan giữa môt số đặc điểm vỉ sinh và kêt quả điều trị: Tỷ lệ $\mathrm{BN}$ có kết quả điều trị tốt ở nhóm cấy dịch ty hầu dương tính là $68,6 \%$ và ở nhóm cấy dịch tỵ hâu âm tính là $82,7 \%$. Như vây, không có sự khác biệt có ý nghĩa thống kê về kết quả điều trị ở nhóm có kết quả cấy dịch tỵ hâu dương tính và âm tính với $p>0,05$.

Tý lệ dương tính với RSV là 18/80 (22,5\%). Kết quả này tương tự nghiên cứu của Sandesh Kini và cs (2019) trền 383 trẻ được chẩn đoán NKHHDCT tỷ lệ nhiễm RSV là 24,5\% [9]. Nghiên cứu của Echavarria M (2018), trên 156 BN
NKHHCT, tỷ lệ nhiễm RSV là 27,4\% [10]. Tỷ lệ BN có kết quả điều trị tốt ở nhóm dương tính với RSV là $83,3 \%$ và nhóm âm tính với RSV là $82,3 \%$ và không có sự khác biêt có ý nghĩa thống kê về kết quả điều trị ở nhóm có kết quả RSV dương tính và âm tính với $p>0,05$

\section{KẾT LUÂ̂N}

Trong 203 BN nghiên cứu tỉ lệ nam găp nhiều hơn nữ, chủ yếu là nhóm trên 12 tháng tuổi, chủ yếu gặp viêm đường hô hấp dưới và VPQP chiếm phần lớn. Không có sự khác biệt về kết quả điều trị liên quan tới độ tuổi, giới tính, số lượng bạch cầu, CRP kết quả cấy DTH và RSV. Thời gian nằm viện của NKHHTCT ngắn hơn so với NKHHDCT.

\section{TÀI LIÊU THAM KHẢO}

1. WHO. Causes of child mortality. WHO, http://ww.who.int/gho/child_health/mortality/caus es/en/, accessed: 05/28/2018

2.Yorita K.L, Holman R.C, Sejvar J.J, et al. (2008). Infectious disease hospitalizations among infants in the United States. Pediatrics, 121(2), 244-252.

3. Nguyễn Thu Nhạn và CS (2002). Mô hình bệnh tật trẻ em. Tâp san Nhi khoa, Tập 10, Tổng hội Y dược hoc Việt Nam, Nhà xuất bản Y hoc.

4. Taksande A.M. and Yeole M. (2015). Risk factors of Acute Respiratory Infection (ARI) in under-fives in a rural hospital of Central India. Journal of Pediatric and Neonatal Individualized Medicine (JPNIM), 5(1), e050105

5. Thanh Minh Hùng (2016). Đăc điểm nhiễm khuẩn hô hấp cấp tính ở trẻ em dưới 5 tuổi điều trị tại Bệnh viện Đa khoa khu vực Ngọc Hồi năm 2016, Kontum

6. Quách Ngọc Ngân, Phạm Thị Minh Hồng (2014). Đặc điểm lâm sàng và vi sinh của viêm phổi công đồng ở trẻ em từ 2 tháng đến 5 tuổi ta bênh viện Nhi Đồng Cần Tho. Tạp chí Y học TP. Hồ Chí Minh , 18 (1), tr. 294-300

7. Feldman A.S, Hartert T.V, Gebretsadik T, et al (2015). Respiratory Severity Score Separates Upper Versus Lower Respiratory Tract Infections and Predicts Measures of Disease Severity. Pediatric Allergy, Immunology, and Pulmonology, 28(2), 117-120.

8. Jorge H. Jaraa, Eduardo Azziz-Baumgartner b, Tirza De Leon (2019). Costs associated with acute respiratory illness and select virus infections in hospitalized children, El Salvador and Panama, 2012-2013. Journal of Infection, 79(2), 108-114.

9. Sandesh Kini, Bhuvanesh Sukhlal Kalal, Sara Chandy (2019). Prevalence of respiratory syncytial virus infection among children hospitalized with acute lower respiratory tract infections in Southern India. World J Clin Pediatr, 8(2), 33-42.

10. Echavarría M, Carballal G (2018). Clinical impact of rapid molecular detection of respiratory pathogens inpatients with acute respiratory infection. Journal of Clinical Virology, 108, 90-95. 